\title{
Economic Load Dispatch Optimization of Six Interconnected Generating Units Using Particle Swarm Optimization
}

\author{
Ravinder Singh Maan ${ }^{1}$, Om Prakash Mahela ${ }^{2}$, Mukesh Gupta ${ }^{3}$ \\ ${ }^{I}$ (Assistant Professor, Dept. of Electrical Engineering, Jaipur National University, Jaipur, India) \\ ${ }^{2}$ (Graduate Student Member IEEE \& Junior Engineer-I, RRVPNL, Jaipur, India) \\ ${ }^{3}$ (Assistant Professor, Department of Electrical Engineering, JNIT Jaipur, India)
}

\begin{abstract}
This paper describe about the optimization of economic loading dispatch (ELD) problem. Economic loading dispatch is one of the important optimization tasks which provide economic condition for a power system. The ELD problems have non-smooth objective function with equality and inequality constraints. This paper presents particle swarm optimization (PSO) method for solving the economic dispatch(ED) problem in power system. The particle swarm optimization is an efficient and reliable evolutionary computational technique, which is used to solve economic load dispatch with line power flows. This paper describes, a new PSO framework used to deal with the equality and inequality constraints in ELD problem. The proposed PSO can always provide satisfying results within a realistic computation time. The PSO is applied with non-smooth cost function. The six thermal units, 26 buses and 46 transmission lines system is used in this paper. The proposed PSO method results are compared with the genetic algorithm (GA) and conventional method to show the effectiveness of PSO method to solve the ELD problems in power system.
\end{abstract}

Keywords- Economic load dispatch, generating unit, genetic algorithm, power system, loss minimization, particle swarm optimization.

\section{INTRODUCTION}

The electric utility systems are interconnected in such a way to achieve the benefits of minimum production cost, maximum reliability and better operating conditions. The economic load dispatch is to minimize the total operating cost of generating units while satisfying system equality and inequality constraints. The economic load dispatch (ELD) is most of power system optimization problem which have complex and non-linear characteristics with heavy equality and inequality. An Economic loading dispatch means minimization of fuel cost of generating unit under some constraints and also reduced transmission losses [1]. The main objective of the optimization problem is to reduce the total generation cost of units while satisfying constraints [3]-[5]. To solve these problems, various salient mathematical approaches have been suggested in the past decades and the multi-objective optimization of power plant such as reduction of fuel cost, heat loss rate, minimize the transmission losses and minimization of pollutant emissions [5]-[7].

The mathematical approaches also include non-linear programming, linear programming [8], Newton based technique [1], Base point and participation method, lambda iteration method [7], gradient method [4]. In this technique the required essential assumption is that the incremental cost curves of the units are monotonically increasing piece wise-linear function but these methods are infeasible because of its non-linear characteristics in practical system [4]-[7].

There are some powerful solution schemes to obtain global optimum solution or to solve ELD problem in power system optimization problems which are Evolutionary technique such as Genetic algorithms (GA), Artificial Neural Network (ANN), Tabu search, Simulated annealing and Particle swarm optimization (PSO). In the past decade, Genetic Algorithm (GA) has been successfully used to solve power optimization problem such as feeder reconfiguration and capacitor placement in a distribution system [4] \& [7].

For solving continuous non-linear optimization problems, the PSO technique is robust; generate high quality solutions within shorter computational time [4] \& [8]. The Genetic algorithm (GA), Evolutionary programming (EP), Artificial Neural Network (ANN) require high computational time and enhanced computational efficiency [9]. The PSO is also easy to implement, flexible mechanism to obtain global optimum solution, sensitive to turning of its parameters, improve the solution quality rapidly and simple in concept [8] \& [10]-[11]. The PSO is employed for complex optimization problem [12]. The PSO method gives the result for lower generation cost compared with other hierarchical methods and provides better solution than others [5]. The PSO is also fast convergence technique. This method considers the maximum and minimum value of each generator limits and line flow. This paper presents the application of PSO method for optimization of Economic Load Dispatch problem of six interconnected generating units and the results are compared with the GA method and conventional method. The results show the superiority of PSO as compared to the Genetic Algorithm and 
conventional method. The ELD problem is represented as a non-smooth optimize problem and to solve these problem various salient method have been proposed.

\section{Particle SWARM OPTIMIZation TeChNIQUe}

Particle swarm optimization (PSO) algorithm was developed by Kennedy and Eberhart in 1995, which is a kind of heuristic global optimization technique [1]-[2]. The PSO method is also applied to various fields of the power system optimization such as reactive power and voltage control, stabilizer design and dynamic security border identification. In practice, an ELD problem is more difficult to obtain optimize problem solution. Particle swarm optimization (PSO) is population based stochastic optimization technique and based on the behaviour of birds flocking or fish schooling (called particle or agent) of a swarm [10]. The study of PSO is performed in two dimensional spaces with the simulation of birds flocking or fish schooling and each bird or fish positions is called agent or particle which is represented in the X-Y coordinates by a point.

The current position of the agent or particle is called pbest value and the pbest value is not in the group of birds. There is some another value which is known as gbest value. The gbest value is defined as the value of the agent or position of the agent in a whole group among pbest of all agents.

Using the concept of velocity, each agent tries to modify its position which is given as:

Where,

$$
v_{i}^{k+1}=\omega v_{i}^{k}+E_{1} \text { rand }_{1} \times\left(\text { pbest }_{i}-c_{i}^{k}\right)+E_{2} \text { rand }_{2} \times\left(\text { gbest }_{i}-c_{i}^{k}\right) .
$$

$\boldsymbol{v}_{\boldsymbol{i}}^{\boldsymbol{k}}=$ velocity of agent $i$ at iteration $k$

$$
\boldsymbol{v}_{\boldsymbol{i}}^{\boldsymbol{k}+\mathbf{1}}=\text { velocity of agent } \mathrm{i} \text { at iteration } \mathrm{k}
$$

$\boldsymbol{\omega}=$ weighting function

$\boldsymbol{c}_{\boldsymbol{i}}^{\boldsymbol{k}}=$ current position of agent $\mathrm{i}$ at iteration $\mathrm{k}$

$\mathbf{E}_{1}$ and $\mathbf{E}_{2}=$ weighting Factors

$\boldsymbol{r a n d}_{1}, \boldsymbol{r a n d}_{2}=$ random number functions Between 0.0 to 1.0

pbest $_{i}=$ personal best of agent $i$

$\boldsymbol{g b e s t}_{\boldsymbol{i}}=$ best value of agent $i$ within whole group

The weighting function is defined as which is used in equation (1):

$$
\omega=\omega_{\max }-\left(\frac{\omega_{\max }-\omega_{\min }}{\text { iter }_{\max }}\right) \text { iter }
$$

Where,

$$
\begin{aligned}
& \boldsymbol{\omega}_{\min }=\text { final Weight } \\
& \boldsymbol{\omega}_{\max }=\text { initial Weight } \\
& \text { iter }_{\text {max }}=\text { maximum Iteration Number } \\
& \text { iter }=\text { current iteration number }
\end{aligned}
$$

The current position (in the swarm) can be modified by the following equation:

$$
c_{i}^{k+1}=c_{i}^{k}+v_{i}^{k+1}
$$

By the equation (1), we can find the gbest model. The inertia weight approach (IWA) is defined using equation (2) in (1). Fig.1 shows the concept of modification of a search point by a PSO.

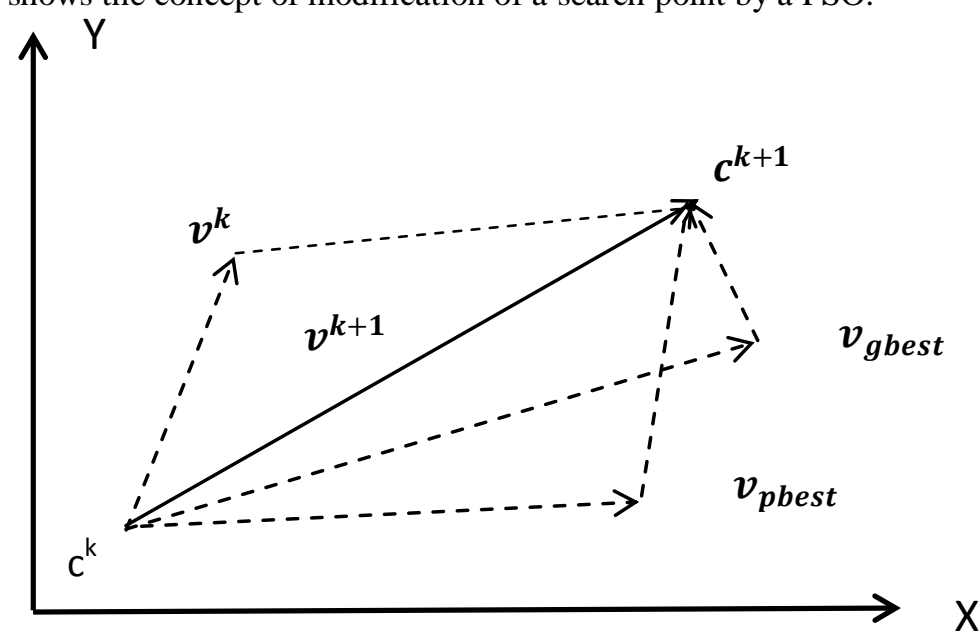

Fig.1 Concept of modification of a searching point by PSO

The value of parameters in equations (1) and (2) are selected as given in Table 1. 
TABLE 1

PARAMETER VALUES

\begin{tabular}{|c|c|c|}
\hline$E_{1}=E_{2}$ & $w_{\max }$ & $w_{\min }$ \\
\hline 2.0 & 0.9 & 0.4 \\
\hline
\end{tabular}

III.

\section{PROBLEM Formulation}

\subsection{Objective Function Formulation}

The main objective of economic load dispatch is that of the minimization of total fuel cost for each generating unit and also reduced the transmission losses with increased each generating unit output also with load demand of power system while satisfying various constraints. The objective function of ELD problem is defined as:

Where,

$$
\begin{gathered}
\operatorname{MinC}_{t}=\sum_{i=1}^{n_{g}} C_{i}\left(P_{i}\right) \\
=\sum_{i=1}^{n_{g}} \alpha_{i}+\beta_{i} P_{i}+\gamma_{i} P_{i}^{2}
\end{gathered}
$$

$\boldsymbol{C}_{\boldsymbol{i}}\left(\boldsymbol{P}_{\boldsymbol{i}}\right)=$ : Generation cost function

$\boldsymbol{\alpha}_{i}, \boldsymbol{\beta}_{i}, \boldsymbol{\gamma}_{i}=$ Cost coefficient of the $i^{\text {th }}$ generator

$\boldsymbol{n}_{\boldsymbol{g}}=$ The total number of dispatchable generating plants

$\boldsymbol{P}_{\boldsymbol{i}}=$ The Generation of the $i^{t h}$ Plant

\subsection{Constraints Formulation}

The power balance and generator operation are the two important constraints while optimizing the economic load dispatch of interconnected generator units. These constraints are as given below:

\section{(i) Power balance}

$$
\sum_{i=1}^{n_{g}} P_{i}=P_{D}+P_{L} \quad\left(i=1, \ldots n_{g}\right)
$$

\section{(ii) Generator operation constraints}

$$
P_{i}^{\min } \leq P_{i} \leq P_{i}^{\max }\left(i=1, \ldots n_{g}\right) \ldots
$$

Where

$\boldsymbol{P}_{i}^{\min }, \boldsymbol{P}_{i}^{\text {max }}=$ are the minimum and maximum output power generation of unit $i$.

The total transmission network losses is a function of unit power output that can be represented using B-coefficient. The simplest quadratic form of transmission network power losses is

$$
P_{L}=\sum_{i=1}^{n_{g}} \sum_{j=1}^{n_{g}} P_{i} B_{i j} P_{j}
$$

A more general formula containing a linear term and a constant term, referred to as Kron's loss formula, is

$$
P_{L}=\sum_{i=1}^{n_{g}} \sum_{j=1}^{n_{g}} P_{i} B_{i j} P_{j}+\sum_{i=1}^{n_{g}} B_{0 i} P_{i}+B_{00}
$$

\section{Proposed Algorithm OF PSo For Solving Eld Problem}

In this paper a new approach to implement the PSO algorithm for solving the economic load dispatch problem is used. The following steps are used while solving the ELD problem by using PSO techniques.

Step 1: Initialize the group (swarm size, initial velocity, particle position).

Step 2: Set the value for iteration count

Step 3: Check for fitness value of each particle

Step 4: If step 3 is satisfactory then update pbest and gbest

Step 5: Update position and velocity using equations (3) and (1)

Step 6: Go to step 3 until satisfying stopping criteria and go to step 7 when stopping criteria is satisfied.

Step 7: Print the final results.

The result of the PSO method is compared with GA method and conventional method. The MATLAB 7.10.0(R2010a) language is used for simulation and executed on an Intel CORE i3 laptop with 4 GB RAM. The flow chart of proposed PSO algorithm for solving ELD problem is shown in Fig. 2. 


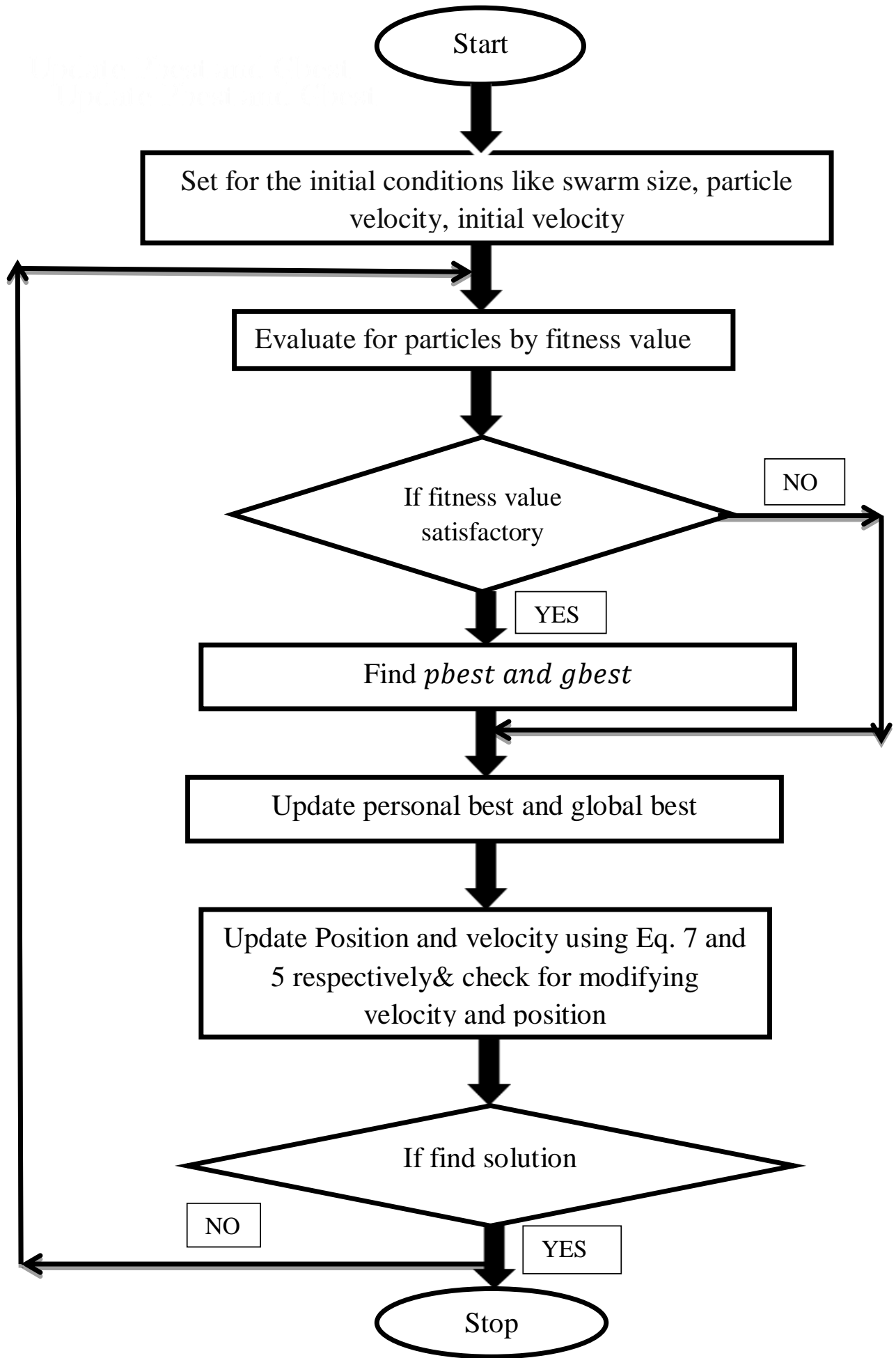

Fig. 2. Flow Chart of Proposed Algorithm for ELD Optimization using PSO

V. SimUlation RESULTS AND DISCUSSION

The six unit test system consisting of six thermal units, 26 buses, and 46 transmission lines is used for simulation of proposed problem of economic load dispatch. This system is simulated for 50 iterations. The characteristics of the six thermal units are given in Table 2. 
TABLE 2

GENERATING UNIT CAPACITY AND COEFFICIENTS

\begin{tabular}{|c|c|c|c|c|c|}
\hline Unit & $\boldsymbol{P}_{\boldsymbol{i}}^{\min }$ & $\boldsymbol{P}_{\boldsymbol{i}}^{\max }$ & $\boldsymbol{\alpha}_{\boldsymbol{i}}(\mathbf{\$})$ & $\boldsymbol{\beta}_{\boldsymbol{i}}(\mathbf{\$} \boldsymbol{M} \boldsymbol{W})$ & $\boldsymbol{\gamma}_{\boldsymbol{i}}\left(\mathbf{\$} \boldsymbol{M W}^{\mathbf{2}}\right)$ \\
\hline 1 & 100 & 500 & 240 & 7.0 & 0.0070 \\
\hline 2 & 50 & 200 & 200 & 10.0 & 0.0095 \\
\hline 3 & 80 & 300 & 220 & 8.5 & 0.0090 \\
\hline 4 & 50 & 150 & 200 & 11.0 & 0.0090 \\
\hline 5 & 50 & 200 & 220 & 10.5 & 0.0080 \\
\hline 6 & 50 & 120 & 190 & 12.0 & 0.0075 \\
\hline
\end{tabular}

The equations used in simulation for fuel cost (Rs /hr) of six generating units are given below:

$$
\begin{gathered}
\boldsymbol{F}_{\mathbf{1 1}}=0.0070 \boldsymbol{P}_{\mathbf{1}}^{2}+7.0 \boldsymbol{P}_{\mathbf{1}}+240 \\
\boldsymbol{F}_{\mathbf{1 2}}=0.0095 \boldsymbol{P}_{\mathbf{2}}^{\mathbf{2}}+10.0 \boldsymbol{P}_{\mathbf{2}}+200 \\
\boldsymbol{F}_{\mathbf{1 3}}=0.0090 \boldsymbol{P}_{\mathbf{3}}^{\mathbf{2}}+8.5 \boldsymbol{P}_{\mathbf{3}}+220 \\
\boldsymbol{F}_{\mathbf{1 4}}=0.0090 \boldsymbol{P}_{4}^{2}+11.0 \boldsymbol{P}_{\mathbf{4}}+200 \\
\boldsymbol{F}_{\mathbf{1 5}}=0.0080 \boldsymbol{P}_{\mathbf{5}}^{\mathbf{2}}+10.5 \boldsymbol{P}_{\mathbf{5}}+220 \\
\boldsymbol{F}_{\mathbf{1 6}}=0.0075 \boldsymbol{P}_{\mathbf{6}}^{\mathbf{2}}+12.0 \boldsymbol{P}_{\mathbf{6}}+\mathbf{1 9 0}
\end{gathered}
$$

The best solution of economic load dispatch optimization of 6 interconnected unit systems is given in Table 3. The results of GA method and conventional method presented in [4] are also given in Table 3. The results of genetic algorithm and conventional methods are used to compare the performance of proposed method. The simulation results of relation between nos. of iterations and fuel cost (Rs /hr) using MATLAB is shown in Fig. 3.

TABLE 3

BEST SOLUTION OF PROPOSED PSO METHOD AND GA*, CONVENTIONAL* METHODS

\begin{tabular}{|c|c|c|c|}
\hline $\begin{array}{c}\text { Unit Power } \\
\text { Output }\end{array}$ & PSO Method & GA Method & Conventional Method \\
\hline P1(MW) & 499.9170 & 444.64 & 474.1196 \\
\hline P2(MW) & 199.5562 & 160.13 & 173.7886 \\
\hline P3(MW) & 299.950 & 278.31 & 190.9515 \\
\hline P4(MW) & 162.5222 & 140.55 & 150.0000 \\
\hline P5(MW) & 199.8994 & 199.58 & 196.7196 \\
\hline P6(MW) & 119.9644 & 107.74 & 103.5772 \\
\hline $\begin{array}{c}\text { Total power } \\
\text { output(MW) }\end{array}$ & $\mathbf{1 5 6 1 . 8 0 9 2}$ & $\mathbf{1 3 3 1 . 3 5}$ & $\mathbf{1 3 2 5 . 6 1}$ \\
\hline $\begin{array}{c}\text { Total Generation } \\
\text { Cost (Rs. /hr.) }\end{array}$ & $\mathbf{1 . 5 2 6 9 e + 0 0 4}$ & $\mathbf{1 . 6 1 9 8 e + 0 0 4}$ & $\mathbf{1 6 7 6 0 . 7 3}$ \\
\hline
\end{tabular}

*Source [4].

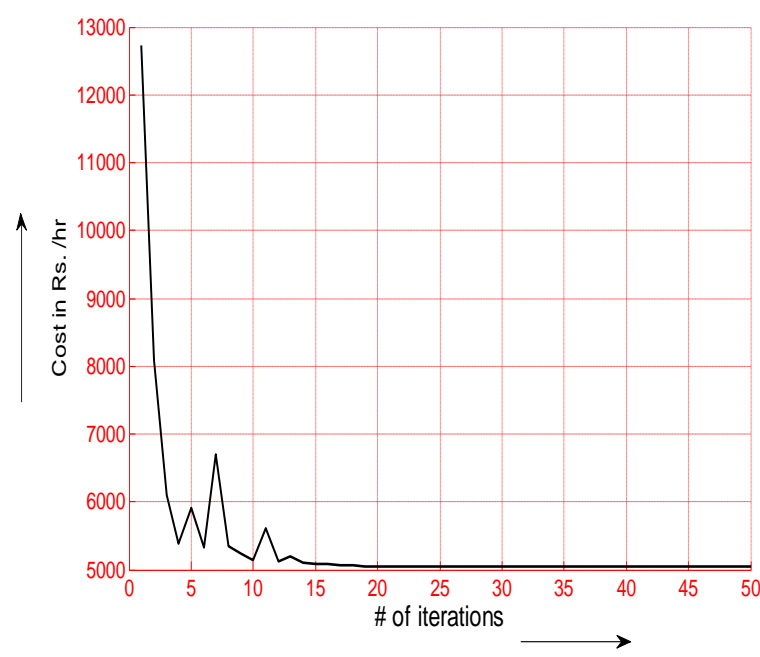

Fig. 3 Relation between Nos. of Iteration and Cost in Rs/ hr 
In this paper, a new approach to solve economic load dispatch problem using PSO method is used. The PSO algorithm provides an optimal solution with less computational time and reasonable number of iterations. The results presented in Table 3 shows that PSO has provided modified results as compared to genetic algorithm and other conventional numerical methods. The PSO technique improves the computational time and convergence. This PSO algorithm is also used to find the optimum solution for the multi-objective problems.

The PSO algorithm gives specified load demand with minimum fuel cost and increased power output for each unit. Therefore, in future the PSO algorithm will be most important and efficient technique to solve the large optimization problems with lower transmission losses because the PSO algorithm is simpler in structure than other methods.

\section{CONCLUSION}

In this paper, the economic load dispatch optimization problem is solved using PSO algorithm successfully. The PSO algorithm is simple in concept, higher solution quality and lower computational time. From the results, we conclude that the PSO algorithm or method is capable to obtain higher quality solution with better convergence property and higher computational efficiency. The PSO algorithm is also used to solve multi-objective optimization problems. The PSO algorithm solves the optimization problems effectively as compared to the genetic algorithm method and conventional methods. The PSO technique is based on experimental trials for searching the particles in the solution space.

\section{REFERENCES}

[1] S.G. Soni, and Dr. M. Pandit, "Hybrid PSO based optimization of emission and economic load dispatch problem," Proceedings National Conference on Advances in Power Systems and Energy Management, May 6-7, 2009, pp 462-467.

[2] G.N. Ajah, and B.O. Anyaka, "Optimization methods and algorithms for solving of hydro-thermal scheduling problems," IOSR Journal of Electrical and Electronics Engineering, Volume 5, Issue 3, Mar. - Apr. 2013, pp. 68-75.

[3] Nagendra Singh, and Yogendra Kumar, "Economic load dispatch with valve point loading effect and generator ramp rate limits constraint using MRPSO," International Journal of Advanced Research in Computer Engineering \& Technology(IJARCET), Volume 2, Issue 4, April 2013, pp 1472-1477.

[4] S.G. Soni, M. Pandit and L.Shrivastava, "Particle swarm optimization technique for solving economic dispatch problem of large power system," National Conference on Advances in Power Systems and Energy Management, March 1- 2, 2008.

[5] Jong-Bae Park, Ki-Song Lee, Joong-Rin Shin, and Kwang Y. Lee, "Economic load dispatch for non-smooth cost functions using particle swarm optimization," IEEE 0-7803-7989-6/03/\$17.00, 2003, pp 938-943.

[6] Jin S. Heo, Kwang Y. Lee, and Raul Garduno-Ramirez, "Multi-objective control of power plants using particle swarm optimization techniques," IEEE Transactions on Energy Conversion, Vol. 21, No. 2, June 2006, pp. 552-561.

[7] A.Zaraki, and M.F.Bin Othman, "Implementing particle swarm optimization to solve economic load dispatch problem," International Conference of soft computing and Pattern Recognition, 2009, DOI 10.1109/SoCPaR.2009, 24.

[8] M.A.Abido, "Optimal power flow using particle swarm optimization" ELSEVIER, 2001, pp.563-571.

[9] Jong-Yul-Kim, Kyeong-Jun Mun, Hyung-Su Kim, and June Ho Park, "Optimal power system operation using parallel processing system and PSO algorithm," International Journal of Electrical Power and Energy System, Vol. 33, 2011, pp. 1457-1461.

[10] Vivek Kumar Jain, and Himmant Singh, "Hybrid particle swarm optimization based reactive power optimization," International Journal of Computational Engineering Research, ISSN: 2250-3005

[11] W. M. Mansour, S. M. Abdelmaksoud, M. M. Salama, and H. A. Henry, "Dynamic economic load dispatch of thermal power system using genetic algorithm," IRACST - Engineering Science and Technology: An International Journal, Vol.3, No.2, April 2013, pp 345-352.

[12] Mousumi Basu, "Bi-objective generation scheduling of fixed head hydrothermal power systems through an interactive fuzzy satisfying method and particle swarm optimization," International Journal of Emerging Electric Power Systems, Vol. 6, Issue 1, 2006.

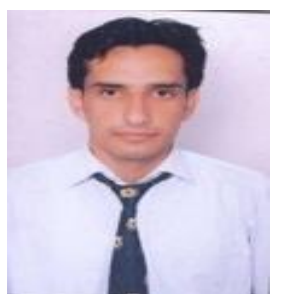

\section{BIOGRAPHIES}

Ravinder Singh Maan was born in Bhathinda in Punjab State of India on March 19, 1991. He studied at Poornima Institute of Engineering \& Technology Jaipur and received the Electrical Engineering degree from Rajasthan Technical University Kota, Rajasthan, India in 2011. He is currently Pursuing M.Tech (Power System) from Jagannath University Jaipur, India.

He has been Assistant Professor with Jaipur National University, Jaipur, India since 2011. His special fields of interest are Application of AI Techniques in Power System and Power Electronics Devices.

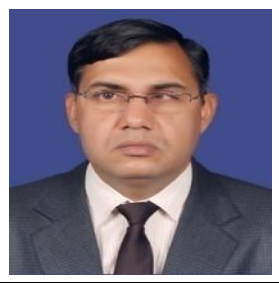

Om Prakash Mahela was born in Sabalpura (Kuchaman City) in the Rajasthan state of India, on April 11, 1977. He studied at Govt. College of Engineering and Technology (CTAE), Udaipur, and received the electrical engineering degree from Maharana Pratap University of Agriculture and Technology (MPUAT), Udaipur, India in 2002. He is currently pursuing M.Tech. (Power System) from Jagannath University, Jaipur, India.

From 2002 to 2004, he was Assistant Professor with the RIET, Jaipur. Since 2004, 
he has been Junior Engineer-I with the Rajasthan Rajya Vidhyut Prasaran Nigam Ltd., Jaipur, India. His special fields of interest are Transmission and Distribution (T\&D) grid operations, Power Electronics in Power System, Power Quality, Load Forecasting and Integration of Renewable Energy with Electric Transmission and Distribution Grid, Applications of AI Techniques in power system. He is an author of 23 International Journals and Conference papers. He is a Graduate Student Member of IEEE. He is member of IEEE Communications Society. He is Member of IEEE Power \& Energy Society. He is Fellow Member of IAEME. He is Reviewer of TJPRC International Journal of Electrical and Electronics Engineering Research. Mr. Mahela is recipient of University Rank certificate from MPUAT, Udaipur, India, in 2002.

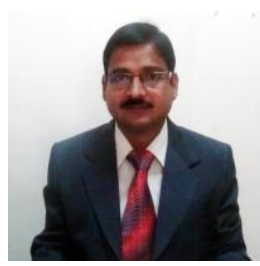

Mukesh Kumar Gupta completed his B.E. Degree in Electronic Instrumentation \& Control Engineering Branch in 1995 and M.E. Degree in Power System in 2009 from Engineering College Kota (RTU Kota) Rajasthan, India and he is pursuing Ph.D on Solar Energy from Jagannath University Jaipur, Rajasthan, India. 